\title{
EXPOSURE TO DIESEL EXHAUST FUMES IN THE CONTEXT OF EXPOSURE TO ULTRAFINE PARTICLES
}

\section{STELLA BUJAK-PIETREK, URSZULA MIKOŁAJCZYKㄹ, IRENA KAMIŃSKA², MALGORZATA CIEŚLAK², and IRENA SZADKOWSKA-STAŃCZYK ${ }^{3}$}

\author{
${ }^{1}$ Nofer Institute of Occupational Medicine, Łódź, Poland \\ Department of Physical Hazards \\ ${ }^{2}$ Textile Research Institute, Łódź, Poland \\ Scientific Department of Unconventional Technologies and Textiles \\ ${ }^{3}$ Nofer Institute of Occupational Medicine, Łódź, Poland \\ Department of Environmental Epidemiology
}

\begin{abstract}
Objectives: Diesel exhaust fumes emission is a significant source of ultrafine particles, the size of which is expressed in nanometers. People occupationally exposed to diesel exhaust particles include mainly workers servicing vehicles with engines of this type. This article presents the analysis of measurements of ultrafine particle concentrations occurring in the bus depot premises during the work connected with everyday technical servicing of buses. Material and Methods: The measurements were carried out in the everyday servicing (ES) room of the bus depot before, during and after the work connected with bus servicing. Determinations included: particle concentrations in terms of particle number and particle surface area, and mass concentrations of aerosol. Results: Mean value of number concentration of 10 - to $1000-\mathrm{nm}$ particles increased almost 20 -fold, from 7600 particles $/ \mathrm{cm}^{3}$ before starting bus servicing procedures to 130000 particles $/ \mathrm{cm}^{3}$ during the bus servicing procedures in the room. During the procedures, the mean surface area concentration of particles potentially deposited in the alveolar (A) region was almost 3 times higher than that of the particles depositing in the tracheo-bronchial (TB) region: $356.46 \mu \mathrm{m}^{2} / \mathrm{cm}^{3} \mathrm{vs} .95 .97 \mu \mathrm{m}^{2} / \mathrm{cm}^{3}$, respectively. The mass concentration of the fraction of particulate matter with aerodynamic diameter $0.02-1 \mu \mathrm{m}\left(\mathrm{PM}_{1}\right)$ increased 5-fold during the analyzed procedures and was $0.042 \mathrm{mg} / \mathrm{m}^{3}$ before, and $0.298 \mathrm{mg} / \mathrm{m}^{3}$ while the procedures continued. Conclusions: At the time when bus servicing procedures continued in the ES room, a very high increase in all parameters of the analyzed particles was observed. The diesel exhaust particles exhibit a very high degree of fragmentation and, while their number is very high and their surface area is very large, their mass concentration is relatively low. The above findings confirm that ultrafine particles found in diesel exhaust fumes may be harmful to the health of the exposed people, and to their respiratory tract in particular.
\end{abstract}

Key words:

Occupational exposure, Ultrafine particles, Diesel engine exhaust, Particles number concentration, Particles surface area concentration, SEM/EDS analysis

\footnotetext{
This work was supported under the grant agreement of Ministry of Science and Higher Education No. 5052/B/P01/2010/38 "Indicators of the exposure to nanoparticles in the workplace and their impact on the respiratory system function." Grant manager: Prof. Irena Szadkowska-Stańczyk.

Received: May 26, 2015. Accepted: October 5, 2015.

Corresponding author: S. Bujak-Pietrek, Nofer Institute of Occupational Medicine, Department of Physical Hazards, św. Teresy 8, 91-348 Łódź, Poland (e-mail: stellab@imp.lodz.pl).
} 


\section{INTRODUCTION}

Exposure to diesel exhaust fumes affects primarily workers of several occupational groups, but may also occur as a result of air contamination in urban environments. These exhaust fumes occur both in atmospheric air, where they become dispersed mainly by transport vehicles such as buses, railway engines, cars and especially trucks, and in the atmospheres of indoor workplaces where equipment and vehicles provided with compression-ignition engines are serviced or operated. The group of workers occupationally exposed to solid particles from exhaust fumes produced by self-ignition engines includes operators of various types of machines (excavators, cranes, forklift trucks, etc.), workers of bus depots, car mechanics, railwaymen, miners, and workers servicing machines with such engines.

Unlike the engines with spark-ignition combustion, where the combusted mixture is rather homogenous, combustion in diesel engines is strongly non-homogeneous. In selfignition engines, diesel oil is injected into a cylinder filled with high-temperature compressed air. The high temperature causes that the mixture of fuel and air is self-ignited. The composition of exhaust fumes produced during that process largely depends on the composition and properties of the diesel oil, conditions prevailing during its combustion or the engine wear. Total combustion of fuels containing hydrocarbons produces exclusively carbon dioxide $\left(\mathrm{CO}_{2}\right)$ and hydrogen oxide $\left(\mathrm{H}_{2} \mathrm{O}\right)$ as the only products. However, although contemporary diesel engines exhibit a high efficacy of combustion - at least $98 \%$, yet incomplete combustion in such engines results in a number of toxic products. The diversity of these products is huge, and their estimated number may be as high as several thousand different chemical compounds occurring as gas or in the form of solid particles.

The basic gaseous components of exhaust fumes emitted by compression-ignition (diesel) engines are: carbon oxides, nitrogen and its compounds, oxygen, steam, sulfur compounds and a vast number of hydrocarbons, mainly aromatic ones.

Nitrogen oxides include 2 compounds: nitrogen monoxide (NO) and nitrogen dioxide $\left(\mathrm{NO}_{2}\right)$, most toxic being nitrogen dioxide, i.e., a brown gas emitting an irritant smell. Incomplete combustion of carbon gives rise to carbon monoxide which, due to its high affinity to hemoglobin, inhibits the systemic transport of oxygen which leads to death. As a result of incomplete combustion of hydrocarbons, these compounds are also found in diesel engine exhaust fumes.

Incomplete combustion of hydrocarbons usually results from too low oxygen/fuel ratio, or from too low temperature in the combustion chamber. Gaseous hydrocarbon components of diesel exhaust include: aliphatic and cyclic hydrocarbons, saturated and unsaturated, containing up to 19 carbon atoms per particle, aldehydes (e.g., formaldehyde, acetic aldehyde, acryl aldehyde), benzene, 1,3-butadiene, polycyclic aromatic hydrocarbons $(\mathrm{PAH})$ and their nitro-derivatives (nitro-PAH) [1,2].

Apart from numerous compounds occurring in the form of gases and vapors, exhaust fumes emitted by diesel engines contain very small solid particles. Emission of ultrafine particles is a phenomenon characteristic of this type of engines. Particles in diesel engine exhaust fumes are largely differentiated both in respect of their physical properties, such as shape or size, and their chemical composition.

Indices describing size and structure of diesel exhaust particles, such as mass, surface area, number, and proportions of particles with different size ranges (size distribution) are essential physical characteristics, both in respect of the feasibility of limiting their emission and their detrimental effects to human health. Those characteristics determine how deep the particles penetrate into the respiratory tract, and thus how much they impair the respiratory function.

Increased emission of ultrafine particles occurs when the engine is not warmed up, especially during its cold start-up, idle running, or when operated at a low load. 
Particles released by diesel engines are usually fine particles identified as particulate matter fraction with aerodynamic diameter $\leq 2.5 \mu \mathrm{m}\left(\mathrm{PM}_{2.5}\right)$, containing a very high proportion of ultrafine particles with diameters below $0.1 \mu \mathrm{m}$. Ultrafine particles are emitted directly from the engine or may arise from condensation of the exhaust gas. In the environment they combine very fast into larger groups and aggregate, and thus their lifetime as independent particles is short $[3,4]$.

Typical diesel particles are usually agglomerates consisting of approx. 15-40 nm diameter basic particles [5]. As the particles are very small, their overall surface area is very large, thus enabling adsorption of various compounds. Furthermore, due to their small size, the particles very easily get into the respiratory tract, reaching the fine pulmonary alveoli [6].

The main component of ultrafine particles in the exhaust fumes of self-ignition engines is elemental carbon in form of soot particles capable of absorbing numerous organic and inorganic compounds on their surface, e.g., hydrocarbons and their derivatives, inorganic compounds of sulfur, nitrates or metals such as lead, platinum, aluminum, calcium $[1,7,8]$.

The chemical composition of ultrafine particles in the exhaust fumes of diesel engines, their number and size, are affected by several factors, including: engine operating conditions, use of solid particles filter, technical condition of the engine, as well as the type of engine fuel [9-12].

The accessible information indicates that exhaust fumes from diesel engines may produce very adverse health effects, including cancer. Health risks manifested by various symptoms may result from acute or chronic exposure. Following acute or short-lasting exposure, diesel exhaust fumes may cause a strong irritation of eyes, throat or bronchi, neurophysiological disorders (dizziness, nausea), and respiratory tract symptoms, e.g., coughing. Chronic exposure may result both in non-neoplastic diseases (e.g., obstructive disorders of pulmonary ventilation) and cancer [1,6,13]. In 2012, the International Agency for Research on Cancer (IARC) classified diesel exhaust fumes as carcinogenic to humans (group 1 of IARC classification). The results of epidemiological studies demonstrate that a chronic exposure to exhaust fumes emitted by selfigniting engines is connected with an increased risk of the development of lung cancer (sufficient evidence) and urinary bladder cancer (limited evidence) [14].

The main factors indicated as a cause of cancer are nanometer-sized particles, on the surface of which some of the organic compounds mentioned above are adsorbed (e.g., PAH), exhibiting carcinogenic or mutagenic effects. This study attempted to asses the concentration of the ultrafine particles released to workplace atmosphere by diesel engines during the maintenance works performed in the bus depot.

\section{MATERIAL AND METHODS}

The measurements were carried out in the room with everyday servicing channel (ES channel). Such a channel serves for everyday inspection of the technical condition of vehicles coming back to the depot after their whole day use. In each vehicle, every day (among other things) the braking system, steering wheel, power transmission system and fluid levels are checked. Then the buses are washed and cleaned inside. There were 2 parallel lines in the room, through which vehicles were passing continually, stopping at consecutive stands. The gates to the room with ES channels were opened when the next bus came in and immediately closed behind it. Two hundred buses were stationed in the depot and 2 hundred buses passed every day through the ES channel.

Evaluation of the degree of releasing nanometric-size particles at the workstations included determination of concentrations (in terms of particle number and their surface area) of nanoparticles potentially deposited in the tracheo-bronchial (TB) or the alveolar (A) regions, and determination of aerosol mass concentration. 
The following devices were used to determine the parameters enabling evaluation of concentrations at workplaces located in the bus depot:

- Condensation Particle Counter (CPC, model 3007-2, TSI, USA) - to determine the number of 10 - to $1000-\mathrm{nm}$ particles in air volume unit (particle number concentration). The number of particles sized below $100 \mathrm{~nm}$ in a given air volume was determined by an indirect method, using the pre-selector for CPC (model 376060) which enables counting - by the apparatus - of particles above a specific diameter (in this case $100 \mathrm{~nm}$ ). The number concentration of particles with 10-100 nm diameter was determined as a difference between the number of all counted particles $(10-1000 \mathrm{~nm})$ and the number of particles counted using the selector (100-1000 nm) in unit volume of air.

- Monitor of Nanoparticles AeroTrak 9000 (TSI, USA) to determine the surface area concentration (particles surface area in unit volume of air) of the particles depositing in tracheo-bronchial region - TB or in pulmonary alveoli $-\mathrm{A}$. The range of the measured particles was $10-1000 \mathrm{~nm}$.

- Monitor of Aerosol Concentration DustTrak (model 8534, TSI, USA) - to determine the mass concentration of aerosol, including dimensional fractions (particles in dimensional range $0.1-15 \mu \mathrm{m}$, fractions $\mathrm{PM}_{1}, \mathrm{PM}_{2.5}$, respirable, particulate matter with aerodynamic diameter $2.5-10 \mu \mathrm{m}\left(\mathrm{PM}_{10}\right)$, total particulate matter).

The measurements were made twice during 2 different measuring days (that were not consecutive working days). The measurement strategy comprised sampling before the procedure connected with technical servicing of vehicles (in the room where there were no buses yet), during the servicing procedure (i.e., with running bus engines), and when it was over. Air was sampled about $1.5 \mathrm{~m}$ above the floor level, in the area corresponding to the workers' breathing zone. Air sampling was performed each time in the same way: for 16 min with 2-min time intervals. The number of samples collected on particular measuring days was 12 samples on the first day and 16 samples collected on the second day of the measurements. The measurements were made in the room through which buses were passing in cycles. Two entrance gates led to the room, opened when the bus was running into it and closed right away.

Simultaneously, air samples were collected at the workplaces by aspiration method onto filters to obtain the samples for scanning electron microscopy and energy dispersive X-ray spectroscopy analysis (SEM/EDS) of the airborne particles. Microscopic analysis SEM/EDS of the filter surface was carried out using the scanning electron microscope VEGA 3 (Tescan, Czech Republic) with an X-ray microanalyzer EDS INCA (Oxford Analytical Instruments, UK), equipped with a monocrystalline silicon lithium (SiLi) detector for the detection of the elements of composite material surfaces from beryllium (Be) to uranium $(\mathrm{U})$ with the maximal spectral resolution $128 \mathrm{eV}$ for $\mathrm{Mn}-\mathrm{K} \alpha$ lines. Three magnifications of $1000 \times, 10000 \times$ and $20000 \times$ were used.

The statistical analysis included determination of arithmetic means, standard deviations, and minimal and maximal values observed during measurements. The statistical significance of differences was assessed using the ANOVA Kruskal-Wallis test and Mann-Whitney U test.

\section{RESULTS}

Detailed results of measurements carried out in the everyday servicing room, including the data from individual measurement days and mean values, are presented in Tables 1-3.

The mean concentration of the number of particles in specified air volume in the room without particle emission source (before the first bus rides in, where there were no vehicles at all for the whole day) reached $7.6 \times 10^{3}$ particles $/ \mathrm{cm}^{3}$, with observed variation 
Table 1. The number concentration of particles from diesel engines exhaust

\begin{tabular}{|c|c|c|c|c|c|}
\hline \multirow{3}{*}{$\begin{array}{l}\text { Measurement day } \\
\text { and process step }\end{array}$} & \multicolumn{4}{|c|}{$\begin{array}{l}\text { Number concentration of particles } \\
{\left[\text { particles } / \mathrm{cm}^{3}\right]}\end{array}$} & \\
\hline & \multicolumn{2}{|c|}{$10-1000 \mathrm{~nm}$} & \multicolumn{3}{|c|}{$10-100 \mathrm{~nm}$} \\
\hline & $\mathrm{AM} \pm \mathrm{SD}$ & min.-max & $\mathrm{AM} \pm \mathrm{SD}$ & $\min .-\max$ & {$[\%]$} \\
\hline \multicolumn{6}{|l|}{ 1st day } \\
\hline before the activity & $8900 \pm 400$ & $8400-9800$ & $6500 \pm 400$ & $6000-7300$ & 73 \\
\hline during activity & $138400 * \pm 30000$ & $96800-205300$ & $116000^{*} \pm 31000$ & $62300-186000$ & 83 \\
\hline after activity & $8560^{* * * *} \pm 10400$ & 64 400-102 300 & $67200^{*} \pm 12100$ & 49 400-83 700 & 78 \\
\hline \multicolumn{6}{|l|}{ 2nd day } \\
\hline before the activity & $6300 \pm 200$ & $5900-6600$ & $4500 \pm 200$ & 4 200-4 900 & 72 \\
\hline during activity & $121700 * \pm 29200$ & $61700-186800$ & $77600^{*} \pm 25500$ & $14700-149700$ & 63 \\
\hline after activity & $88600^{* * * *} \pm 28200$ & $46700-151000$ & $69600^{* * * *} \pm 28600$ & $26900-134800$ & 77 \\
\hline \multicolumn{6}{|l|}{ 1st and 2nd day together } \\
\hline before the activity & $7600 \pm 300$ & $7200-8200$ & $5500 \pm 300$ & $5100-6100$ & 72 \\
\hline during activity & $130000 * \pm 29600$ & $79300-196100$ & $96800^{*} \pm 28300$ & $38500-167900$ & 73 \\
\hline after activity & $87100^{* * * *} \pm 19300$ & $55600-126600$ & $68400^{*, * *} \pm 20400$ & 38 200-109 200 & 77 \\
\hline
\end{tabular}

$\mathrm{AM}$ - arithmetic mean; SD - standard deviation; min. - minimal value; max - maximal value.

* Statistical significance of differences between mean values (before-during activity; before-after activity) $(\mathrm{p}<0.05)$.

** Statistical significance of differences between mean values during-after activity $(\mathrm{p}<0.05)$.

Table 2. Surface area concentration of particles potentially deposited in the alveolar (A) and tracheo-bronchial (TB) region, emitted by the vehicles with diesel engine

\begin{tabular}{|c|c|c|c|c|}
\hline \multirow{3}{*}{$\begin{array}{l}\text { Measurement day } \\
\text { and process step }\end{array}$} & \multicolumn{4}{|c|}{$\begin{array}{c}\text { Surface area concentration } \\
{\left[\mu \mathrm{m}^{2} / \mathrm{cm}^{3}\right]}\end{array}$} \\
\hline & \multicolumn{2}{|c|}{ alveolar fraction } & \multicolumn{2}{|c|}{ tracheo-bronchial fraction } \\
\hline & $\mathrm{AM} \pm \mathrm{SD}$ & $\min .-\max$ & $\mathrm{AM} \pm \mathrm{SD}$ & $\min .-\max$ \\
\hline \multicolumn{5}{|l|}{ 1st day } \\
\hline before the activity & $29.0 \pm 1.3$ & $27.6-31.4$ & $6.1 \pm 0.20$ & $5.9-6.5$ \\
\hline during activity & $279.6^{*} \pm 226.1$ & $125.1-1374.4$ & $67.1^{*} \pm 38.20$ & $27.9-178.5$ \\
\hline after activity & $145.2^{*, * *} \pm 61.7$ & $73.0-283.5$ & $52.0 * \pm 28.40$ & $30.8-119.1$ \\
\hline \multicolumn{5}{|l|}{ 2nd day } \\
\hline before the activity & $18.6 \pm 0.3$ & $18.2-19.2$ & $4.3 \pm 0.05$ & $4.3-4.4$ \\
\hline during activity & $433.3^{*} \pm 197.9$ & $54.4-863.8$ & $124.8^{*} \pm 56.70$ & $25.3-269.9$ \\
\hline after activity & $133.1^{*, * *} \pm 62.7$ & $83.7-240.6$ & $16.8^{*, * *} \pm 3.10$ & $12.8-22.5$ \\
\hline \multicolumn{5}{|l|}{ 1st and 2nd day together } \\
\hline before the activity & $23.8 \pm 0.8$ & $23.0-25.3$ & $5.2 \pm 0.10$ & $5.1-5.5$ \\
\hline during activity & $356.5^{*} \pm 212.0$ & $89.8-1119.1$ & $96.0 * \pm 47.40$ & $26.6-224.2$ \\
\hline after activity & $139.2^{*, * *} \pm 62.2$ & $78.4-262.1$ & $34.4^{*, * *} \pm 15.80$ & $21.8-70.8$ \\
\hline
\end{tabular}

Abbreviations as in Table 1. 


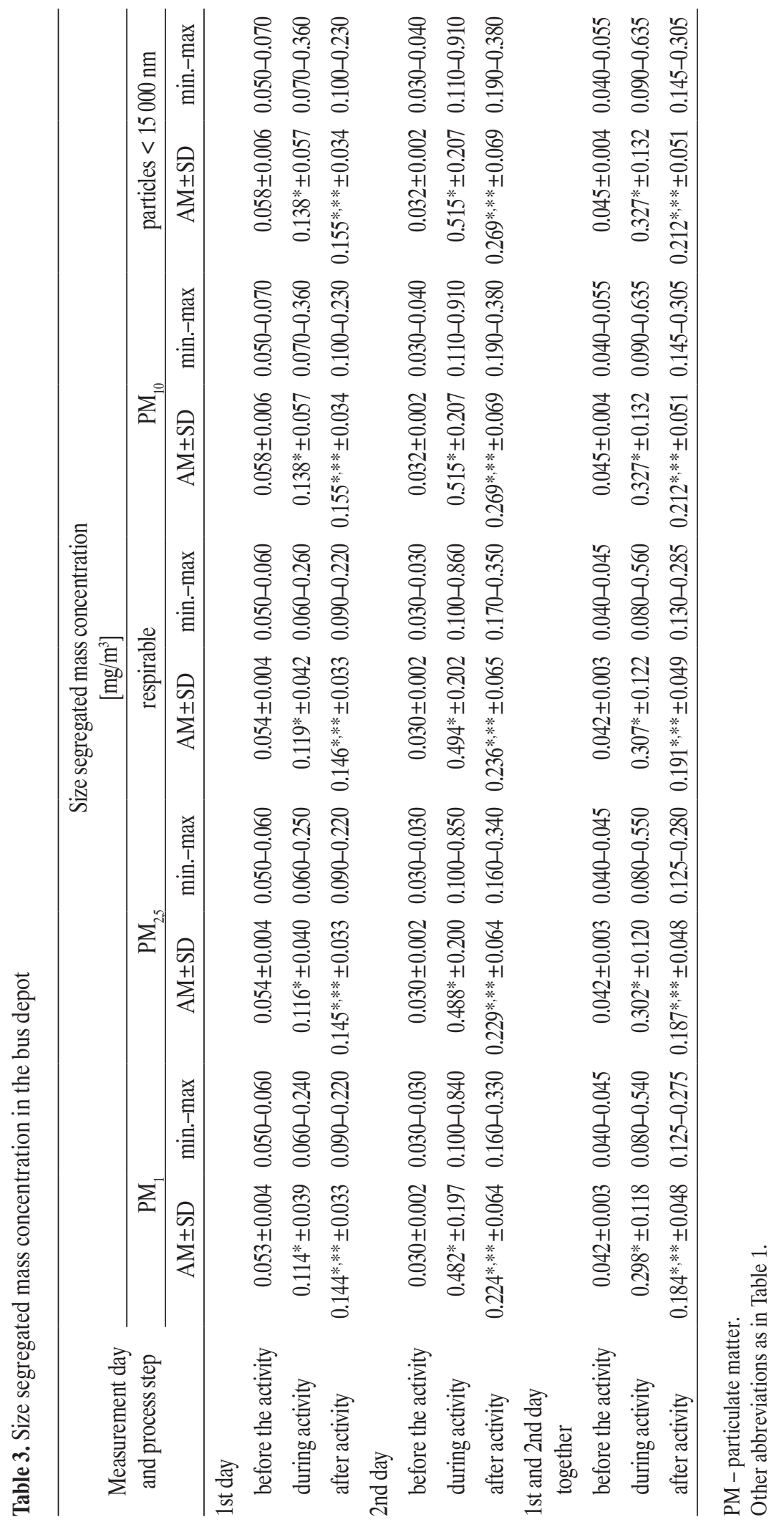


for respective measurement days within: $8.9 \times 10^{3}$ particles $/ \mathrm{cm}^{3}$ on the first day and $6.3 \times 10^{3}$ particles $/ \mathrm{cm}^{3}$ on the second day of measurements. After the start of the work in the ES room, the particle concentration was higher and its mean value during that stage reached: $130 \times 10^{3}$ particles $/ \mathrm{cm}^{3}\left(138.4 \times 10^{3}\right.$ particles $/ \mathrm{cm}^{3}$ and $121.7 \times 10^{3}$ particles $/ \mathrm{cm}^{3}$ on the first and second day of the measurements, respectively). Once the work in the ES room was completed, the mean number concentration of particles gradually returned to its initial state and during the measurement reached $87.1 \times 10^{3}$ particles $/ \mathrm{cm}^{3}$ and was contained within the range from $85.6 \times 10^{3}$ particles $/ \mathrm{cm}^{3}$ to $88.6 \times 10^{3}$ particles $/ \mathrm{cm}^{3}$ during the first and second day of the research.

The observed changes were statistically significant $(\mathrm{p}<0.05)$. The mean percentage of $\leq 100 \mathrm{~nm}$ particles in the total pool of particles was not changed significantly during consecutive stages of the research and in most cases constituted over $70 \%$ of all measured particles, whereas changes during particular measurement days did not exceed $10 \%$ (Table 1).

Figure 1 depicts the trends of changes in the level of number concentration of 10-1000-nm and 10-100-nm particles during the measurement on the selected measurement day. An increase in the mean number concentration of particles for all particles counted by means of CPC and the particles having diameters $<100 \mathrm{~nm}$, observed when the work in the ES room started, was over 17-fold.

Significantly increasing was also the surface area concentration of the particles when buses traveled along the everyday servicing channel. Variation resulting from the data in this range within 2 different days is presented in Table 2. Before the activities connected with inspection of vehicles started, the mean values of particles surface area concentration was $23.8 \mu \mathrm{m}^{2} / \mathrm{cm}^{3}$ for the fraction potentially deposited in pulmonary alveoli and $5.2 \mu \mathrm{m}^{2} / \mathrm{cm}^{3}$ for the tracheo-bronchial fraction, respectively. Once the work started, i.e., while the buses were in the everyday servicing

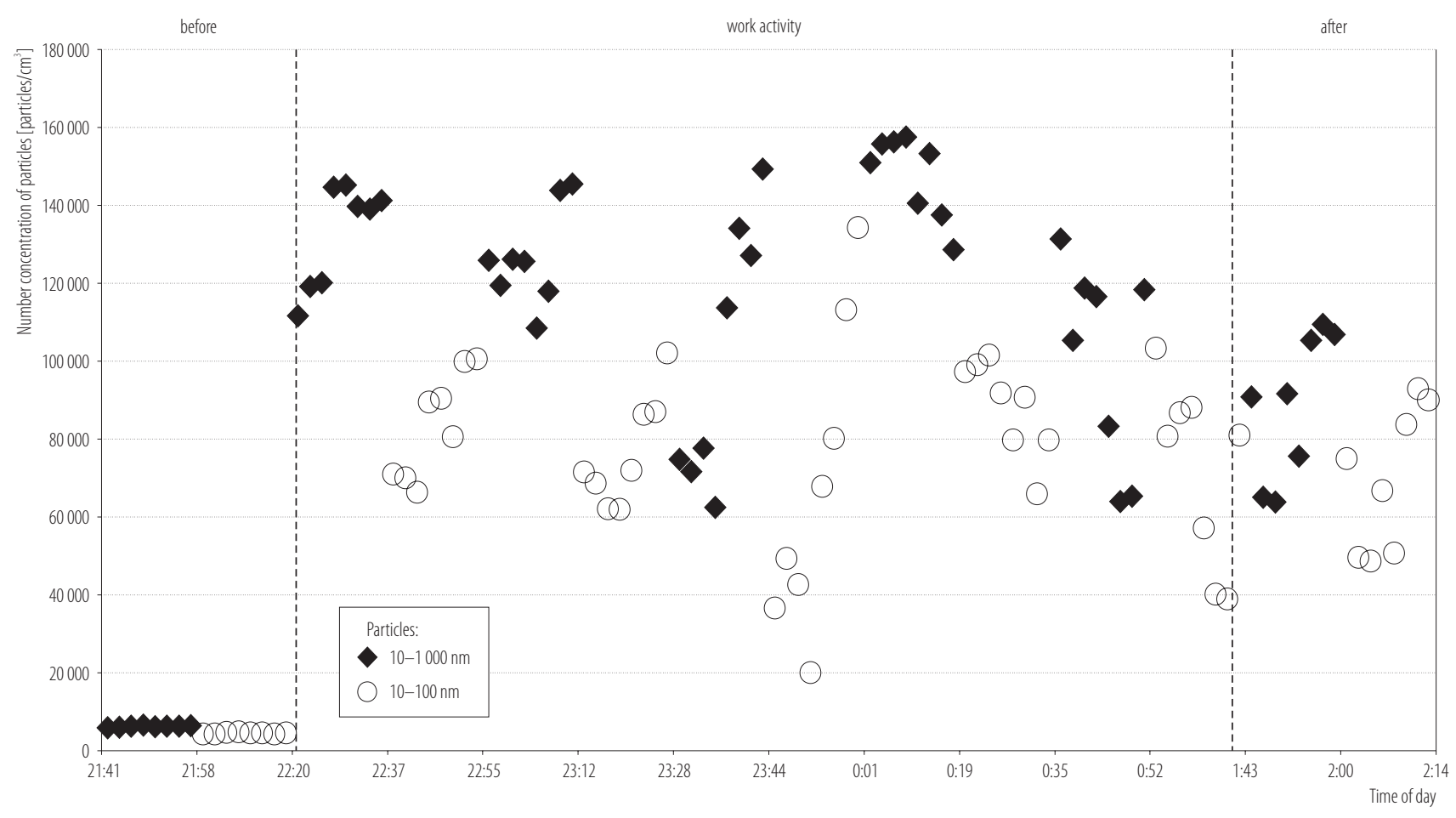

Fig. 1. Number concentration of particles emitted from diesel engines 
room, these concentrations were at a significantly higher level: $356.4 \mu \mathrm{m}^{2} / \mathrm{cm}^{3}$ for fraction A and $95.9 \mu \mathrm{m}^{2} / \mathrm{cm}^{3}$ for the TB fraction.

As results from the above data, this parameter, very often acknowledged as the most significant index of exposure, increased over 15-fold in the room while the vehicles were present on ES stands. When the work was over in the ES room, the surface area concentration of the particles was lower, as compared to the status when the vehicles were shifted from one location to another in the ES channel. It was $139.1 \mu \mathrm{m}^{2} / \mathrm{cm}^{3}$ for fraction A and $34.3 \mu \mathrm{m}^{2} / \mathrm{cm}^{3}$ for fraction TB. The observed changes were statistically significant. Irrespective of the level of concentrations of both fractions and the stage of the testing process, the surface area concentration of the particles potentially deposited in pulmonary alveoli was on average 3-4 times higher than the concentration of the fraction deposited in the tracheobronchial part.
While the buses were translocated through the ES room, the dynamically changing levels of concentrations related to 2-min time intervals were observed. Figure 2 illustrates the variability of the levels of surface area concentration for the particles released from running diesel engines noted during an exemplary measurement day.

The mass concentration of the particles released with exhaust fumes of running bus engines was determined for respective measurement fractions: $\mathrm{PM}_{1}, \mathrm{PM}_{2.5}$, respirable fraction, $\mathrm{PM}_{10}$ and the fraction of all particles in a measurable range of the apparatus, i.e., 100-15 $000 \mathrm{~nm}$ (total fraction of particles). The results of the measurements of mass concentrations of particles including their dimensional fractions and differentiation of results related to different measurement days are presented in Table 3. Before the work was started in the everyday servicing room, the mean mass concentration of aerosol of fraction $\mathrm{PM}_{1}$, corresponding to particles $<1000 \mathrm{~nm}$ was $0.042 \mathrm{mg} / \mathrm{m}^{2}$ (with daily mean

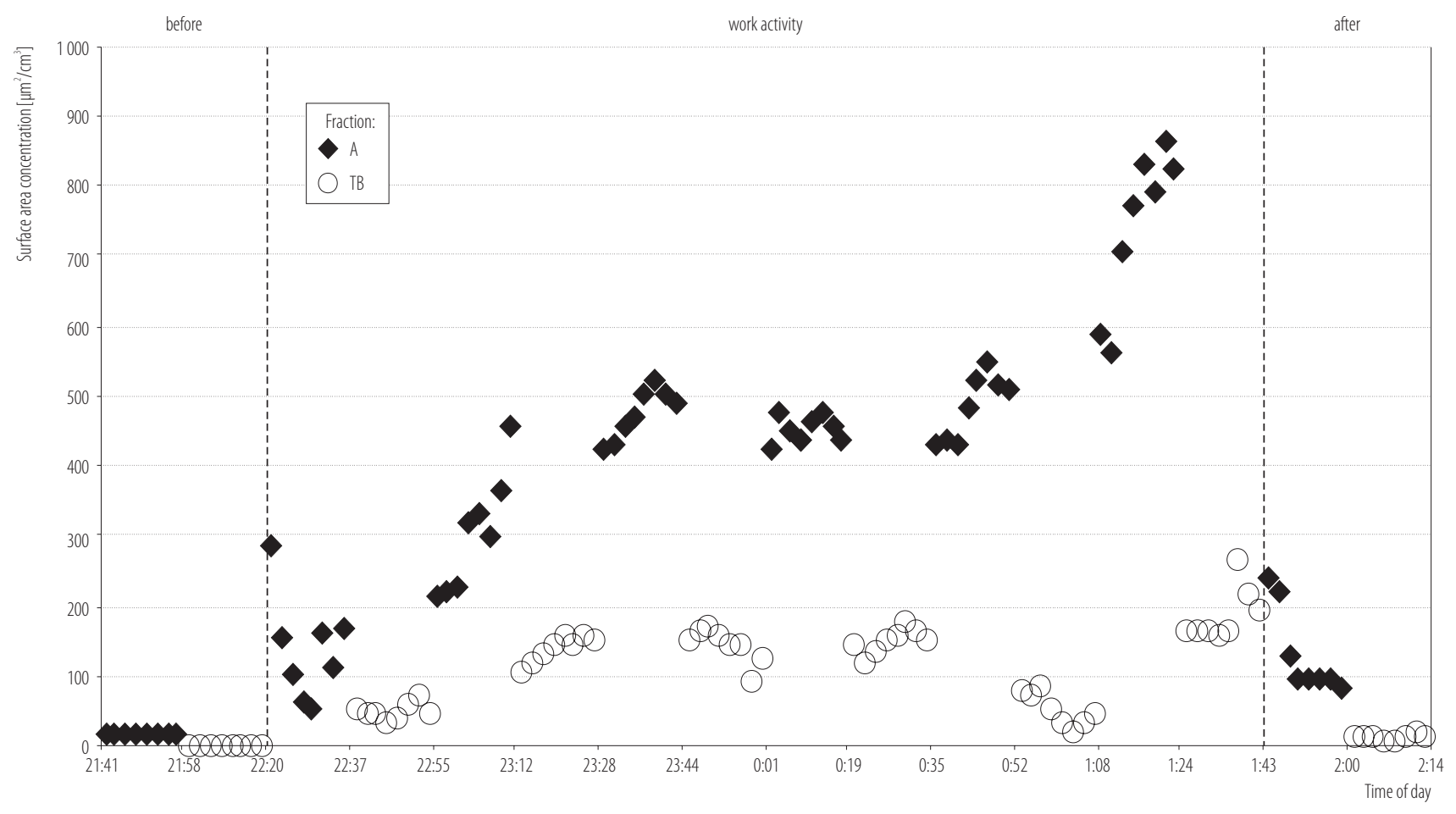

A - alveolar; TB - tracheo-bronchial.

Fig. 2. Surface area concentration of particles emitted by the vehicles with diesel engine 
values $0.053 \mathrm{mg} / \mathrm{m}^{3}$ and $0.03 \mathrm{mg} / \mathrm{m}^{3}$ on the first and second day of measurements, respectively) and increased 7-fold, to value $0.298 \mathrm{mg} / \mathrm{m}^{3}\left(0.114 \mathrm{mg} / \mathrm{m}^{3}\right.$ on the first day, and $0.482 \mathrm{mg} / \mathrm{m}^{3}$ on the second day) at the time when buses were systematically moving through the room.

The mean mass concentration of 100-15 $000 \mathrm{~nm}$ particles, constituting a fraction of all particles counted by DustTrak, reached $0.045 \mathrm{mg} / \mathrm{m}^{3}\left(0.058 \mathrm{mg} / \mathrm{m}^{3}\right.$ on the first day and $0.032 \mathrm{mg} / \mathrm{m}^{3}$ on the second day) before the work started in the ES room, whereas during the works connected with buses moving through the room it was increasing, similarly as in case of $\mathrm{PM}_{1}, 7$-fold, to the $0.327 \mathrm{mg} / \mathrm{m}^{3}$ level $\left(0.138 \mathrm{mg} / \mathrm{m}^{3}\right.$ and $0.515 \mathrm{mg} / \mathrm{m}^{3}$ on the first and second day, respectively). Once the activities carried out in everyday servicing room were over, the mass concentration of individual fractions of particles varied depending on the measurement day; on the first day of the measurements that concentration still remained at a high level, or was even slightly higher, whereas on the second day it was lower by over 50\%. In case of fraction $\mathrm{PM}_{1}$, the mean daily concentration values after the end of the work in the ES room was $0.144 \mathrm{mg} / \mathrm{m}^{3}$ on the first day and $0.224 \mathrm{mg} / \mathrm{m}^{3}$ on the second day of the measurements. The same values determined for all 100-15 000-nm particles were: $0.155 \mathrm{mg} / \mathrm{m}^{3}$ during the first measurement and $0.269 \mathrm{mg} / \mathrm{m}^{3}$ during the next one. The mean value of mass concentration of fraction $\mathrm{PM}_{1}$ reached then $0.184 \mathrm{mg} / \mathrm{m}^{3}$ and that of all 100-15 000-nm particles reached $0.212 \mathrm{mg} / \mathrm{m}^{3}$. All changes in mass concentration observed during the study were statistically significant.

Figure 3 presents the development of the levels and trends of changes in mass concentration of fraction $\mathrm{PM}_{1}$ particles and total particles fraction, i.e., all particles counted by the apparatus, during the whole exemplary measuring period.

Figures 4-6 present the comparisons of consecutive parameters, depicting the relations between ongoing

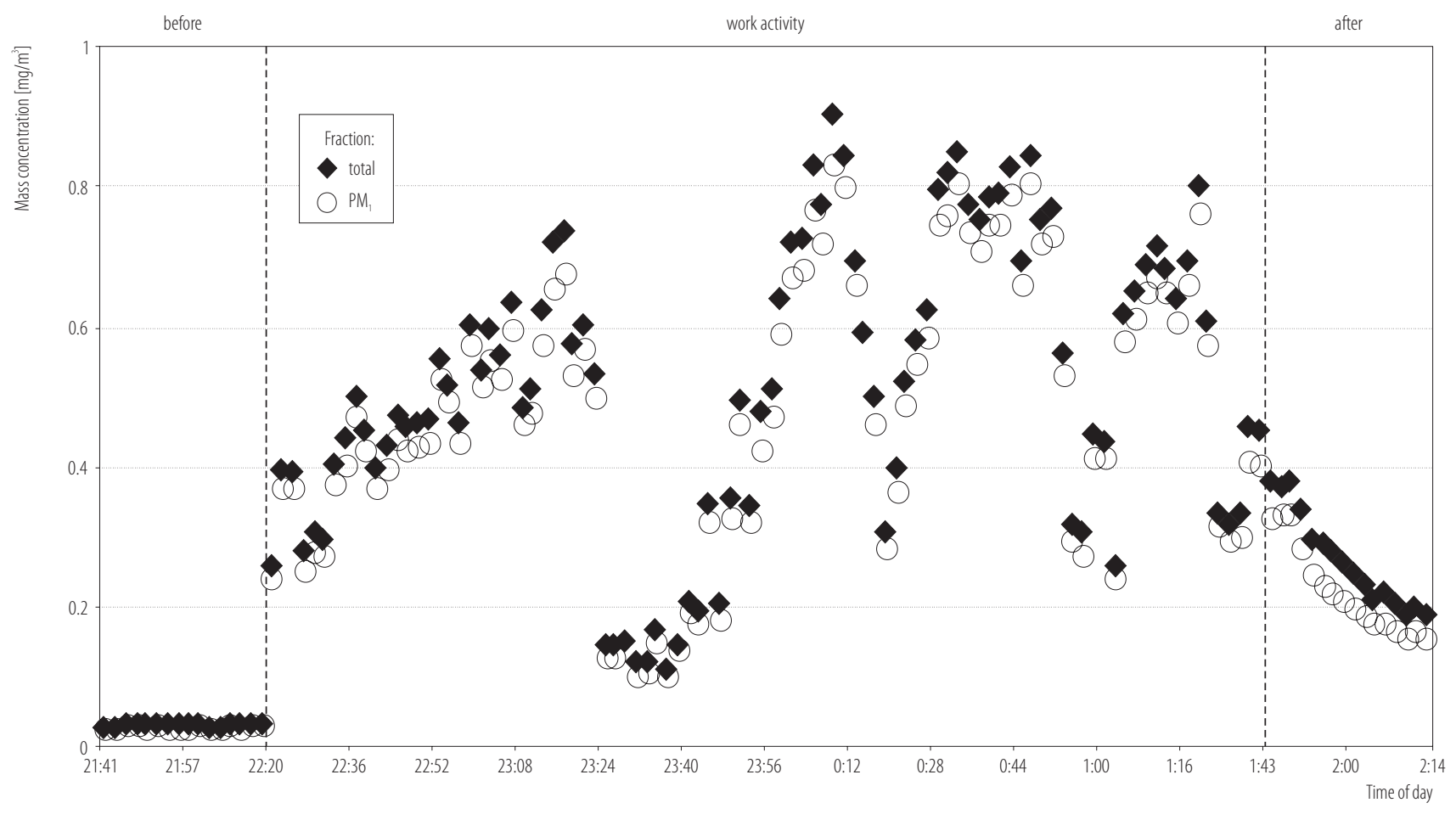

$\mathrm{PM}_{1}$ - particulate matter with aerodynamic diameter 0.02-1 $\mu \mathrm{m}$.

Fig. 3. Mass concentration of $\mathrm{PM}_{1}$ and total particles $<15000 \mathrm{~nm}$ in the bus depot 


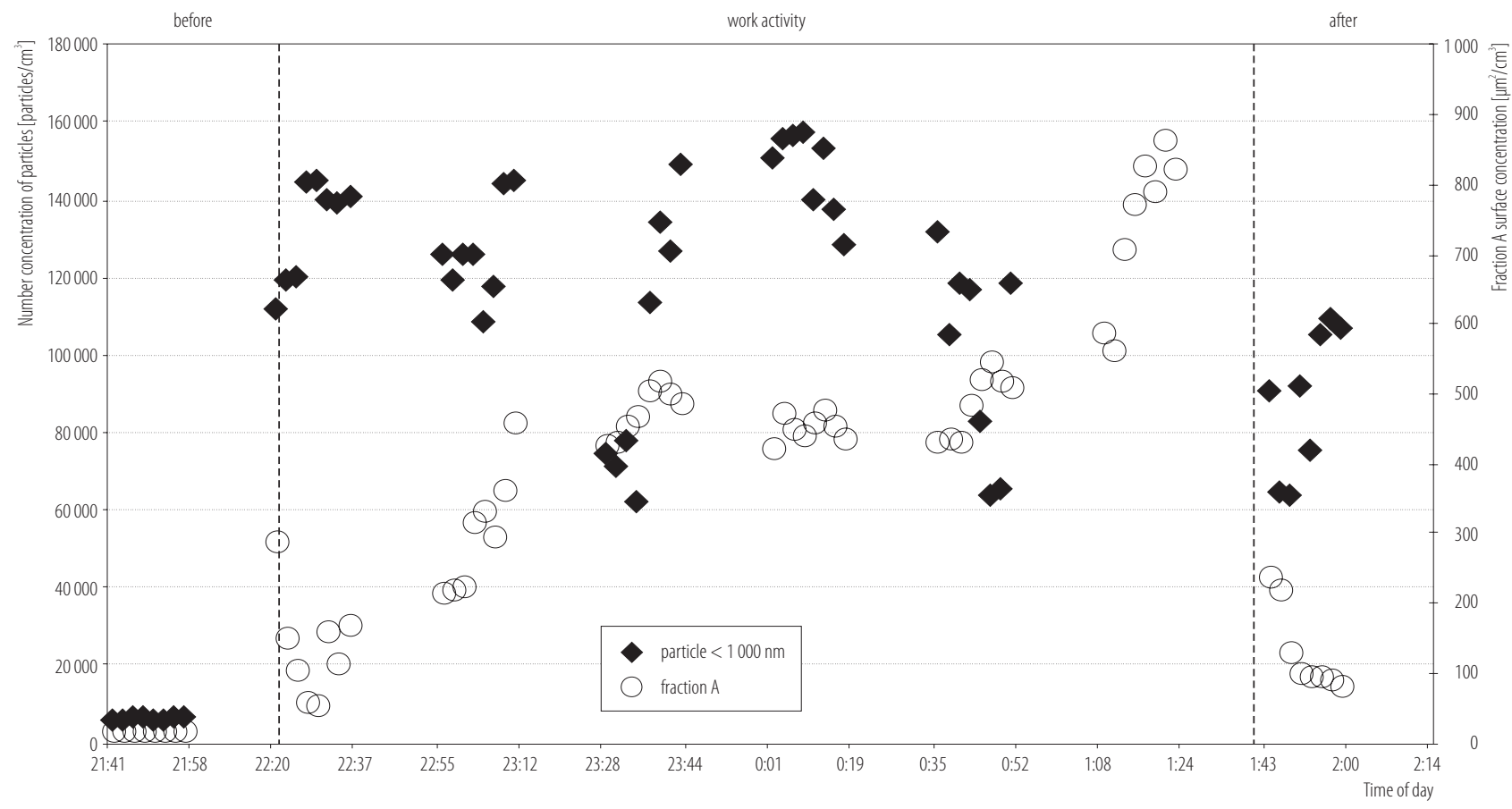

A - alveolar.

Fig. 4. Number and surface area (fraction A) concentration of 10-1000-nm particles

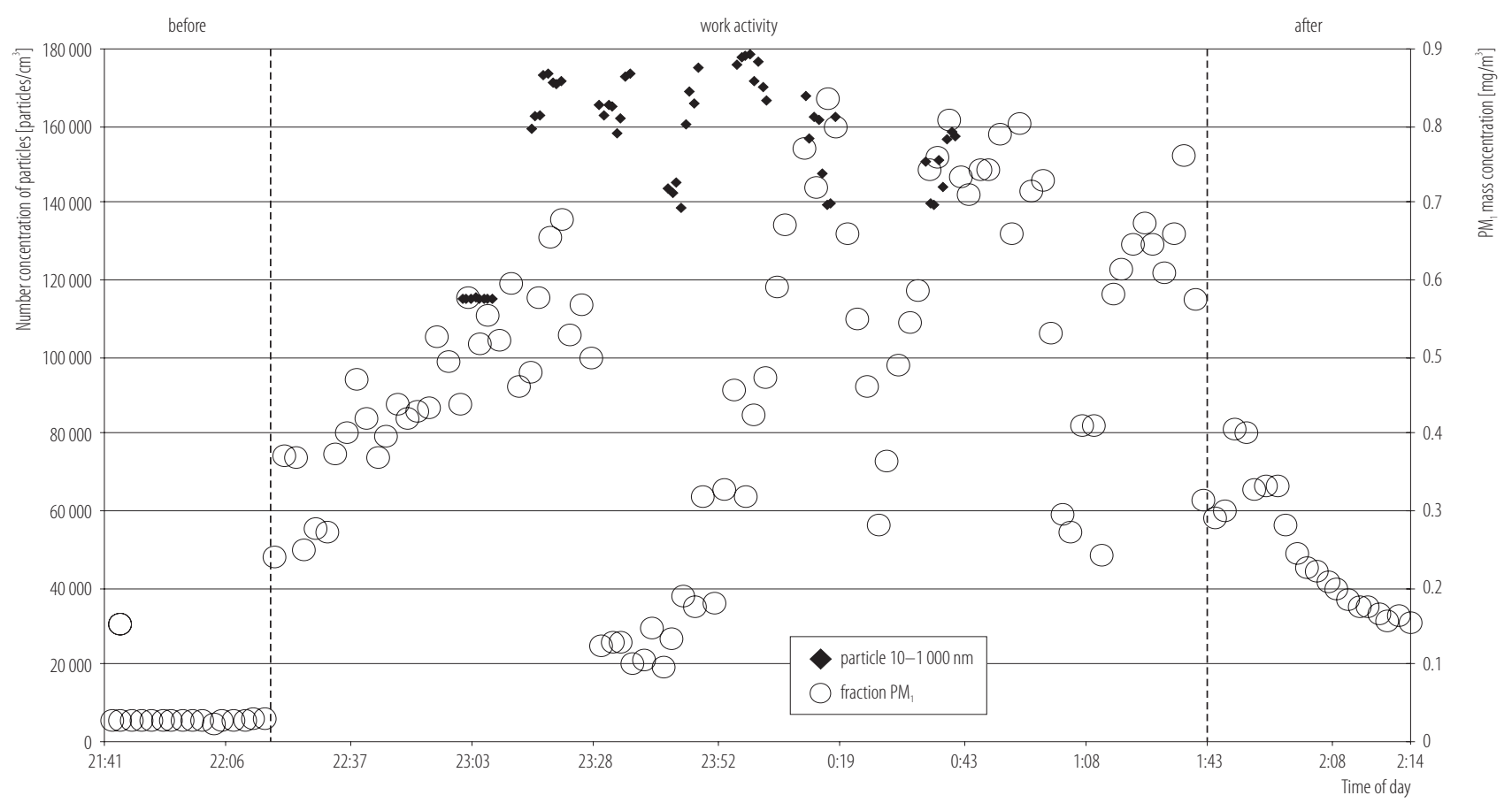

$\mathrm{PM}_{1}$ - particulate matter with aerodynamic diameter $0.02-1 \mu \mathrm{m}$.

Fig. 5. Number $(10-1000 \mathrm{~nm})$ and mass $\left(\mathrm{PM}_{1}\right)$ concentration of particles 


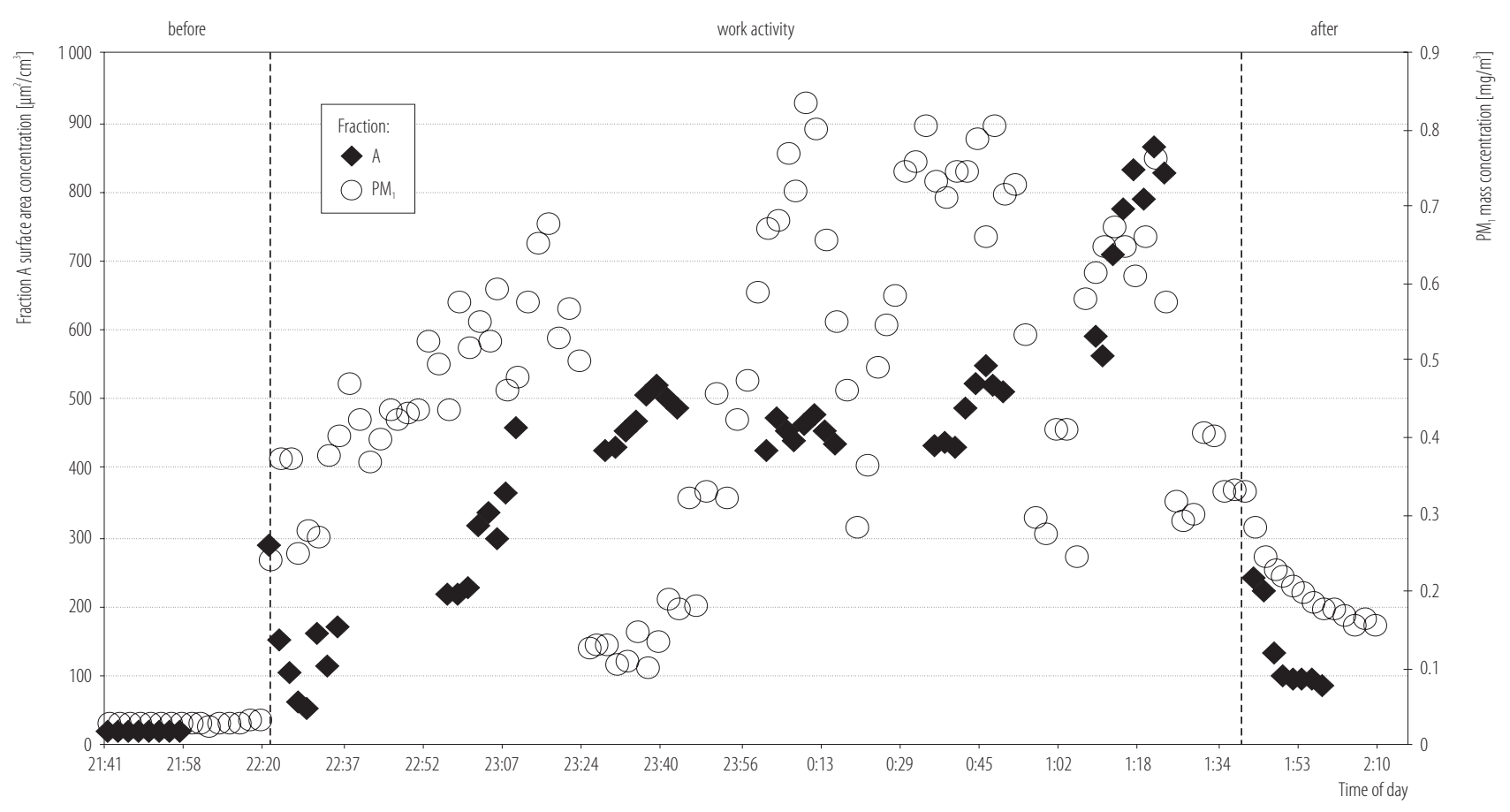

A - alveolar; $\mathrm{PM}_{1}$ - particulate matter with aerodynamic diameter 0.02-1 $\mu \mathrm{m}$.

Fig. 6. Surface area concentration (fraction $\mathrm{A}$ ) and mass concentration $\left(\mathrm{PM}_{1}\right)$ of particles

changes in tested factors and their trends on the selected measuring day. The comparison below shows that with high dynamics of changes going on during the process, we can observe that an increase in the number concentration of particles $\leq 1000 \mathrm{~nm}$ is almost simultaneous with an increase in surface area concentration of the alveolar fraction (A) of particles emitted by diesel engines (Figure 4). It was also found out that with increasing number concentration of 100-1000 nm particles, the mass concentration of fraction $\mathrm{PM}_{1}$ was also increasing, as presented in Figure 5. Graphical presentation of the variation of surface area concentration of fraction A particles and fraction $\mathrm{PM}_{1}$ mass concentration is given in Figure 6. Also in this case the surface area concentration increase was accompanied by increased mass concentration of $100-1000-\mathrm{nm}$ particles.

\section{Results of SEM analysis}

Photo 1 shows the SEM images of the filter surface. energy dispersive X-ray spectroscopy (EDS) analysis showed the presence of the following elements: carbon (C), oxygen $(\mathrm{O})$, sodium $(\mathrm{Na})$, aluminium $(\mathrm{Al})$, silicon $(\mathrm{Si})$ and sulphur (S) (Table 4). It was found that the presence of $\mathrm{Al}$ and Si has a local character (Spectrum 1). Other elements are present in all tested areas (Spectra 1-5).

\section{DISCUSSION}

The occurrence of a number of various hazards and adverse health effects resulting from exposure to individual components of diesel exhaust fumes is particularly important in the case of workers servicing the devices or vehicles with such engines, performing their occupational activities in rooms, workshops, or other indoor locations. The principles of carrying out the measurements and methods used in evaluation of occupational exposure to harmful agents, including carcinogens, were comprehensively described in scientific literature and also in legal provisions and standards $[15,16]$. The value of the highest admissible 

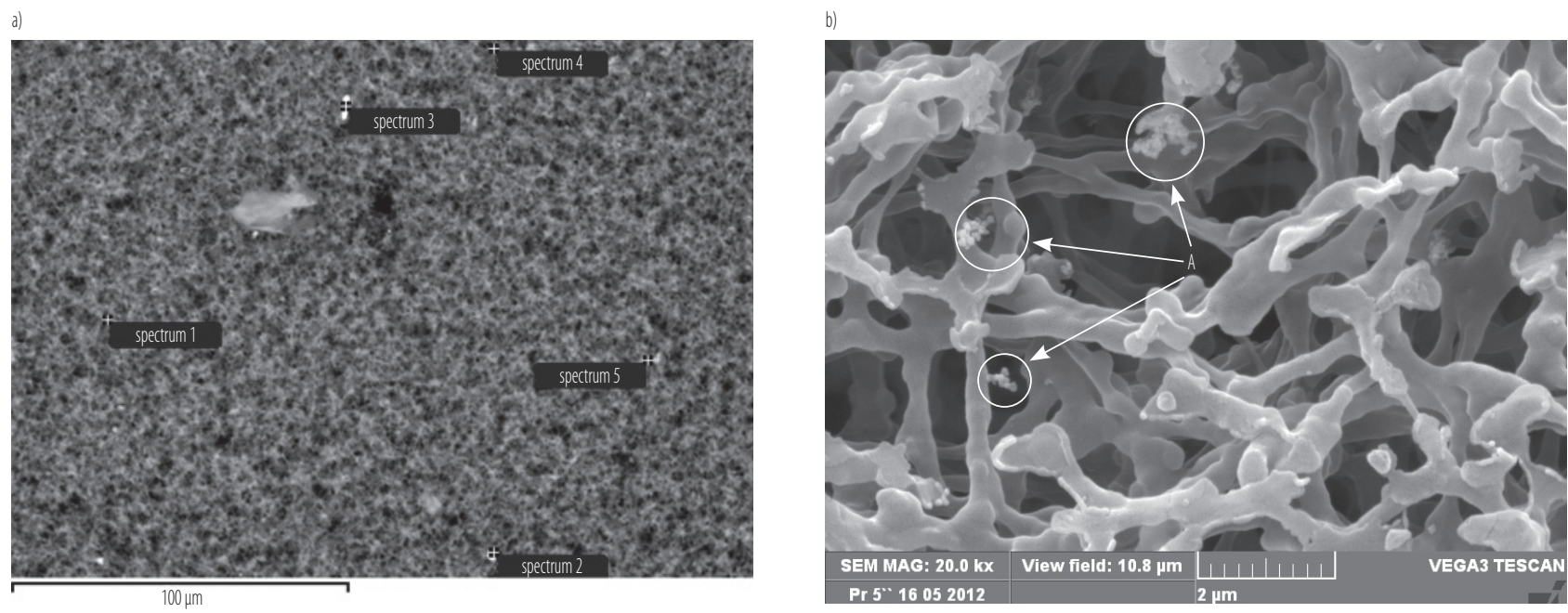

A - agglomerates of particles with diameter $<0.1 \mu \mathrm{m}$.

Photo 1. Scanning electron microscopy (SEM) images of the filter surface: magnification a) $1000 \times$ and b) $20000 \times$

Table 4. The weight percentage of the elements on the tested filter surface

\begin{tabular}{lccccccc}
\hline \multirow{2}{*}{ Spectrum } & \multicolumn{9}{c}{$\begin{array}{c}\text { Element } \\
{[\mathrm{wt} \%]}\end{array}$} & $\begin{array}{c}\text { Total } \\
{[\mathrm{wt} \%]}\end{array}$ \\
\cline { 2 - 7 } & $\mathrm{C}$ & $\mathrm{O}$ & $\mathrm{Na}$ & $\mathrm{Al}$ & $\mathrm{Si}$ & $\mathrm{S}$ & \\
\hline 1 & 46.17 & 53.19 & 0.18 & 0.11 & 0.14 & 0.21 & 100 \\
2 & 47.02 & 52.59 & 0.19 & - & - & 0.20 & 100 \\
3 & 49.74 & 49.84 & 0.21 & - & - & 0.21 & 100 \\
4 & 52.36 & 47.22 & 0.24 & - & - & 0.18 & 100 \\
5 & 53.07 & 46.55 & 0.20 & - & - & 0.18 & 100 \\
Min.-max & $46.17-53.07$ & $46.55-53.19$ & $0.18-0.24$ & $0.11-0.11$ & $0.14-0.14$ & $0.18-0.21$ & - \\
\hline
\end{tabular}

$\mathrm{C}$ - carbon; $\mathrm{O}$ - oxygen; $\mathrm{Na}$ - sodium; $\mathrm{Al}$ - aluminium; $\mathrm{Si}$ - silicon; $\mathrm{S}$ - sulfur.

Min. - minimal value; max - maximal value.

concentration of respirable fraction of solid particles in diesel engine exhaust fumes is $0.5 \mathrm{mg} / \mathrm{m}^{3}[1,17]$.

However, the currently used methods do not comprise determination of the concentration of ultrafine particles included in diesel exhaust fumes. This publication presents the results of analysis based on measurements of concentration of submicron particles found in exhaust fumes emitted by diesel engines. The analysis comprises not only the mass concentration which is the most frequently determined parameter in the evaluation of exposure to aerosols containing ultrafine particles, but also other parameters very important due to the potential health effects, such as the number concentration and surface area concentration of particles potentially deposited in the tracheo-bronchial and the alveolar regions of the respiratory tract. Measurements were carried out in the everyday servicing room of the bus depot. Air was sampled at the $1.5 \mathrm{~m}$ height - in the breathing zone of workers performing the works connected with on-going technical inspection of buses. 
The above analysis indicates that the mean number concentration in case of particles with sizes up to $1000 \mathrm{~nm}$ increased 17-fold during the works performed in the ES room, as compared to the value before the activities connected with buses passing through the room, and was at the level of $130 \times 10^{3}$ particles $/ \mathrm{cm}^{3}$. The $10-100-\mathrm{nm}$ particles constituted $70 \%$ of that number.

A high increase in the number concentration of the ultrafine particles, along with those sized below $100 \mathrm{~nm}$, was also observed in the test carried out at the garage workstations after $5 \mathrm{~min}$ and $8 \mathrm{~min}$ from the moment the diesel engine was switched on [18]. In the study carried out in 9 warehouses where the source of particles emission were diesel engines of continually used forklift trucks, the values of the number concentrations of particles sized $0.02-1 \mu \mathrm{m}$ were determined. The results for the above range of particle sizes differed considerably because the measurements were carried out in different warehouses. The mean (weighted) values of number concentration of the particles noted in the study ranged from $50 \times 10^{3}$ particles $/ \mathrm{cm}^{3}$ to $218 \times 10^{3}$ particles $/ \mathrm{cm}^{3}$ [19].

In another study, which evaluated the exposure to diesel exhaust fumes of people waiting at a bus station, it was found out that at an average time of the passengers waiting for the bus, which was $4.7 \mathrm{~min}$, the mean value of number concentration of the particles was $14.1 \times 10^{3}$ particles $/ \mathrm{cm}^{3}$. Observed was also - depending on the daytime - a pattern of changes in the number of particles found in the air at the waiting stations. The highest number concentrations of particles were noted in the morning and afternoon-evening hours of the traffic peak with a clearly decreased particle concentration at the noon hours [20]. Those values were lower than ours because, in that instance, the measurements were conducted in open air.

Another parameter analyzed in this study, describing the exposure to ultrafine particles emitted from diesel engines, was the surface area concentration of the particles (i.e., concentration of particles expressed in terms of the surface area of the particles per unit volume of air). The increase in the value of this concentration during the works performed in the bus room was significant both for the fraction of particles potentially deposited in the pulmonary alveoli part and in the tracheo-bronchial portion of the lungs; however, the degree of changes was different depending on the day on which the measurements were carried out. On the first measurement day the surface area concentration of the particles of both fractions increased about 10-fold, whereas on the second day a 23-fold increase in the concentration was observed for fraction A and almost 3-fold increase for the TB fraction. Up to now, few studies on exposure to particles involve determination of surface area concentration of particles. The most frequently performed measurements, consisting in determination of mass concentration, are more and more often accompanied by determination of the concentration in terms of the number of particles emitted into the environment (as it often happens in case of determination of exposure to ultrafine particles in communal environment) [21-23]. The surface area concentration of particles is a parameter determined sporadically, usually in experimental rather than real conditions.

In the research monitoring the surface area concentration of particles deposited in the alveolar part of lungs of people staying near a busy street with frequently passing trucks and buses, the values of that parameter were found to differ considerably, depending on the day of the week in which the measurements were made. The mean values of surface area concentration of particles noted in this study ranged from $34.9 \mu \mathrm{m}^{2} / \mathrm{cm}^{3}$ to $89.2 \mu \mathrm{m}^{2} / \mathrm{cm}^{3}$; it was observed that on working days the concentration was on average twice higher than during the weekend. During that study, also high fluctuations were found in the value of fraction A particles surface area concentration during a single day, for example at the highest noted mean concentration the results obtained during the whole day ranged from $27.4 \mu \mathrm{m}^{2} / \mathrm{cm}^{3}$ to $510.5 \mu \mathrm{m}^{2} / \mathrm{cm}^{3}$ [24]. Equally 
high fluctuation in the value of surface area concentration of particles deposited in pulmonary alveoli was observed in this study. The corresponding results obtained within one measurement day during the works performed in the ES room ranged between $54.4 \mu \mathrm{m}^{2} / \mathrm{cm}^{3}$ and $863.8 \mu \mathrm{m}^{2} / \mathrm{cm}^{3}$.

In experimental studies conducted at the Lund University [25], apart from other parameters, such as particles number concentration and mass concentration, the particles dimensional distribution, morphology and size of single particles, also the surface area of diesel exhaust fume particles was determined. The surface area of the emitted particles estimated in that study, assuming the spherical particles, was $2.1 \times 10^{-4} \mathrm{~cm}^{2} / \mathrm{cm}^{3}\left(21000 \mu \mathrm{m}^{2} / \mathrm{cm}^{3}\right)$. The area of the aggregates formed in the exhaust fumes was estimated at $3.5 \times 10^{-4} \mathrm{~cm}^{2} / \mathrm{cm}^{3}\left(35000 \mu \mathrm{m}^{2} / \mathrm{cm}^{3}\right)$. This study estimated also the dose deposited in lungs during 3-h exposure and indicated that the surface area of particles deposited after that time would be $95.7 \mathrm{~cm}^{2}$, assuming that the emitted particles are single balls, and $151.9 \mathrm{~cm}^{2}$ considering the aggregates. The concentrations determined in our study amounted to $279.6 \mu \mathrm{m}^{2} / \mathrm{cm}^{3}$ and $433.6 \mu \mathrm{m}^{2} / \mathrm{cm}^{3}$, and were much lower than those obtained in laboratory conditions.

This study determined also mass concentration of particles emitted by diesel engines, including their dimensional fractions. The concentration of the finest fractions of the determined particles, i.e., $\mathrm{PM}_{1}$ (100-1000-nm) fraction during the work going on in the ES room reached $0.114 \mathrm{mg} / \mathrm{m}^{3}$ on the first measuring day and $0.482 \mathrm{mg} / \mathrm{m}^{3}$ on the second day and was in both cases 7 times higher than before the works. A similar increase in the concentration was observed in case of all analyzed particles in size range from $100 \mathrm{~nm}$ to $<15000 \mathrm{~nm}$. The concentrations of that fraction at the time when the buses were moving in and out of the room was $0.138 \mathrm{mg} / \mathrm{m}^{3}$ and $0.515 \mathrm{mg} / \mathrm{m}^{3}$, respectively, depending on the measurement day.
The concentrations of respirable dust noted in the study performed in very similar conditions, in the bus depot workshop where the sources of exposure were the buses moving in and out of the inspection, repair and cleaning stands, were within $267 \mu \mathrm{g} / \mathrm{m}^{3}\left(0.267 \mathrm{mg} / \mathrm{m}^{3}\right)$ in case of individual measurements and $211 \mu \mathrm{g} / \mathrm{m}^{3}\left(0.211 \mathrm{mg} / \mathrm{m}^{3}\right)$ in case of the measurement conducted in the background [26]. In our study, the concentration of respirable fraction of dust on consecutive measurement days reached $0.119 \mathrm{mg} / \mathrm{m}^{3}$ and $0.494 \mathrm{mg} / \mathrm{m}^{3}$, and considering a high fluctuation of the analyzed parameter during a single measurement, we may assume that the value was only approximate.

In the study mentioned before [18], carried out in a garage with running diesel engine, the mass concentration of particles sized $0.1-10 \mu \mathrm{m}$ was at the level of $0.772 \mathrm{mg} / \mathrm{m}^{3}$ $5 \mathrm{~min}$ after the engine was switched on and $0.896 \mathrm{mg} / \mathrm{m}^{3}$ after 8 min.

In the research carried out in warehouse rooms where forklift trucks with diesel engines were used, the values of concentration (geometric concentration) of respirable dust determined gravimetrically (individual dosimetry) differed considerably, depending on the warehouse in which the measurements were made, ranging from $<80 \mu \mathrm{g} / \mathrm{m}^{3}\left(0.08 \mathrm{mg} / \mathrm{m}^{3}\right)$ to $179 \mu \mathrm{g} / \mathrm{m}^{3}\left(0.179 \mathrm{mg} / \mathrm{m}^{3}\right)$ [19]. The mean mass concentration of particles constituting fraction $\mathrm{PM}_{1}$, determined in the study carried out in a group of 20 workers employed in the warehouse as mechanics performing repair works or other activities connected with buses and trucks, staying inside the premises, amounted to $22.8 \mu \mathrm{g} / \mathrm{m}^{3}\left(0.228 \mathrm{mg} / \mathrm{m}^{3}\right)$ [27].

Scanning electron microscopy (SEM) analysis confirmed that diesel exhaust particles are agglomerates consisting of $<0.1 \mu \mathrm{m}$ diameter basic particles. Energy dispersive $\mathrm{X}$-ray spectroscopy (EDS) analysis indicates that following elements were present in the samples: carbon, oxygen, sodium, aluminium, silicon and sulphur. In another study on particulate matter in vehicle fuels [28], exhaust SEM analysis also exhibits an agglomeration of 
many tiny particles. In this study it was observed that particle size ranged from $0.04 \mu \mathrm{m}$ to $0.12 \mu \mathrm{m}$. In the samples, the presence of carbon, oxygen and silicon was observed as in our study.

The data obtained during this study show a high differentiation of analyzed parameters, depending on the measurement day. Furthermore, even during one day, we could observe very high dynamics of changes in the values of concentrations within all analyzed parameters. This results from considerable differences in the conditions during the measurements. The considerable variation in numerical values of the analyzed parameters was affected by such unavoidable factors as: air motion caused by opening of gates when buses moved in or passed to consecutive stands in the room, diversity of vehicles in the fleet (different makes, years of production, types and wear of engines) or the time for which buses remained on the stand where they were inspected, and whether the engine was switched off or idling.

\section{CONCLUSIONS}

While the work was performed in the everyday servicing room of the bus depot, a very high increase was observed in all parameters of analyzed solid particles.

Exhaust fumes emitted by diesel engines contain a large number of very small (submicron) particles with large surface area and a relatively low mass concentration, and that is why a comprehensive evaluation of exposure should include all analyzed parameters.

Those findings confirm that ultrafine particles found in diesel exhaust fumes may be harmful to the health of the exposed people, and to their respiratory tract in particular.

\section{REFERENCES}

1. Czerczak S, Szymczak W, Lebrecht G, Hanke W. [Diesel exhaust - Documentation of proposed limit values of occupational exposure]. Podstawy Metody Oceny Srod Pr. 2005;3(45):89-133. Polish.
2. United States Environmental Protection Agency. Health assessment document for diesel engine exhaust. Washington (DC): The Agency; 2002.

3. Kittelson DB. Engines and nanoparticles: A review. J Aerosol Sci. 1998;29(5-6):575-88, http://dx.doi.org/10.1016/ S0021-8502(97)10037-4.

4. Ono-Ogasawara M, Smith TJ. Diesel exhaust particles in the work environment and their analysis. Ind Health. 2004;42:389-99, http://dx.doi.org/10.2486/indhealth.42.389.

5. Burtscher H. Physical characterization of particulate emissions frm diesel engines: A review. J Aerosol Sci. 2005;36: 896-932, http://dx.doi.org/10.1016/j.jaerosci.2004.12.001.

6. Wichmann HE. Diesel exhaust particles. Inhal Toxicol. 2007;19 Suppl. 1:241-4, http://dx.doi.org/10.1080/08958 370701498075.

7. Lebrechert G, Czerczak S. [Diesel exhaust. Health risk assessment guidelines for carcinogens. No. 6]. Łódź: Instytut Medycyny Pracy; 1997. p. 42-84. Polish.

8. Pośniak M. [Diesel combustion exhaust: Principles and methods of occupational exposure assessment]. Med Pr. 2003; 54(4):389-93. Polish.

9. Samy S, Zielinska B. Secondary organic aerosol production from modern diesel engine emissions. Atmos Chem Phys. 2010;10(2):609-25, http://dx.doi.org/10.5194/acp-10-609-2010.

10. Zielinska B, Samy S, McDonald JD, Seagrave JC; HEI Health Review Committee. Atmospheric transformations of diesel emissions. Res Rep Health Eff Inst. 2010;(147):5-60.

11. Konstandopoulos AG, Zarvalis D, Dolios I. Multi-instrumental assessment of diesel particulate filters. SAE Technical Paper Series 2007 No. 2007-01-0313. Warrendale (PA): Society of Automotive Engineers; 2007, http://dx.doi.org/ 10.4271/2007-01-0313.

12. Davies B. 2002 William P. Yant Award Lecture. Diesel particulate control strategies at some Australian underground coal mines. AIHA J. 2002;63(5):554-8.

13. Hesterberg TW, Long CM, Bunn WB, Lapin CA, McClellan RO, Valberg PA. Health effects research and regulation of diesel exhaust: An historical overview focused 
on lung cancer risk. Inhal Toxicol. 2012;24 Suppl 1:1-45, http://dx.doi.org/10.3109/08958378.2012.691913.

14. International Agency for Research on Cancer. IARC: Diesel engine exhaust carcinogenic. Press release No. 213 (12 June 2012). Lyon: The Agency; 2012.

15. [Regulation of the Minister of Health of 2 February 2011 concerning the tests and measurements of agents harmful to health in the workplace environment. J Laws 2011, No. 33, item 166]. Polish.

16. Pośniak M, Jankowska E, Szewczyńska M, Zapór L, Brochocka A, Pietrowski P. [Hazard of diesel engines exhaust]. Warszawa: Centralny Instytut Ochrony Pracy - Państwowy Instytut Badawczy; 2010. Polish.

17. [Regulation of the Minister of Labour and Social Affairs of 6 June 2014 concerning the highest admissible concentrations and volume of agents harmful in the workplace environment. J Laws 2014, item 817]. Polish.

18. Jankowska E, Pośniak M. [Concentration and size distribution of diesel fume particles in garage air]. Bezpiecz Pr. 2010;1:23-6. Polish.

19. Wheatley AD, Sadhra S. Occupational exposure to diesel exhaust fumes. Ann Occup Hyg. 2004;48(4):369-76.

20. Yip M, Madl P, Wiegand A, Hoffmann W. Exposure assessment of diesel bus emissions. Int J Environ Res Public Health. 2006;3(4):309-15, http://dx.doi.org/10.3390/ijerph2006030038.

21. Wang Y, Zhu Y, Salinas R, Ramirez D, Karnae S, John K. Roadside measurements of ultrafine particles at a busy urban intersection. J Air Waste Manage Assoc. 2008;58:144957, http://dx.doi.org/10.3155/1047-3289.58.11.1449.
22. Ruuskanen J, Tuch T, Ten Brink H, Peters A, Khlystov A, Mirme A, et al. Concentrations of ultrafine, fine and $\mathrm{PM}_{2.5}$ particles in 3 European cities. Atmos Environ. 2001;35: 3729-38, http://dx.doi.org/10.1016/S1352-2310(00)00373-3.

23. Molnar P, Janhall S, Hallquist H. Roadside measurements of fine and ultrafine particles at a major road north of Gothenburg. Atmos Environ. 2002;36:4115-23, http://dx.doi. org/10.1016/S1352-2310(02)00183-8.

24. Albuquerque PC, Gomes JF, Bordado JC. Assessment of exposure to airborne ultrafine particles in the urban environment of Lisbon, Portugal. J Air Waste Manage Assoc. 2012;62(4): 373-80, http://dx.doi.org/10.1080/10962247.2012.658957.

25. Wierzbicka A, Nilsson PT, Rissler J, Sallsten G, Xu Y, Pagels JH, et al. Detailed diesel exhaust characteristics including particle surface area and lung deposited dose for better understanding of health effects in human chamber exposure studies. Atmos Environ. 2014;86:212-9, http://dx.doi. org/10.1016/j.atmosenv.2013.11.025.

26. Groves J, Cain JR. A survey of exposure to Diesel engine exhaust emission in the workplace. Ann Occup Hyg. 2000;44(6):435-47.

27. Lewine M, Plato N, Gustavsson P. Exposure to particles, elemental carbon and nitrogen dioxide in workers exposed to motor exhaust. Ann Occup Hyg. 2007;51(8):693-701, http:// dx.doi.org/10.1093/annhyg/mem046.

28. Bhattacharjee A, Mandal H, Roy M, Chini TK. A preliminary study on the nature of particulate matters in vehicle fuel wastes. Environ Monit Assess. 2011;176:473-81, http:// dx.doi.org/10.1007/s10661-010-1598-x.

This work is available in Open Access model and licensed under a Creative Commons Attribution-NonCommercial 3.0 Poland License - http://creativecommons.org/ licenses/by-nc/3.0/pl/deed.en. 